Article

\title{
Improving Rheological and Mechanical Properties of Various Virgin and Recycled Polypropylenes by Blending with Long-Chain Branched Polypropylene
}

\author{
Sascha Stanic ${ }^{1, *}$, Thomas Koch ${ }^{1}$, Klaus Schmid ${ }^{2}$, Simone Knaus ${ }^{3}$ and Vasiliki-Maria Archodoulaki ${ }^{1}$ \\ 1 Institute of Materials Science and Technology, TU Wien, Getreidemarkt 9, 1060 Vienna, Austria; \\ thomas.koch@tuwien.ac.at (T.K.); vasiliki-maria.archodoulaki@tuwien.ac.at (V.-M.A.) \\ 2 Pergan GmbH, Schlavenhorst 71, 46395 Bocholt, Germany; dr.schmid@pergan.com \\ 3 Institute of Applied Chemistry, TU Wien, Getreidemarkt 9, 1060 Vienna, Austria; simone.knaus@tuwien.ac.at \\ * Correspondence: sascha.stanic@tuwien.ac.at; Tel.: +43-(1)-5880130869
}

\section{check for} updates

Citation: Stanic, S.; Koch, T.; Schmid K.; Knaus, S.; Archodoulaki, V.-M. Improving Rheological and Mechanical Properties of Various Virgin and Recycled Polypropylenes by Blending with Long-Chain Branched Polypropylene. Polymers 2021, 13, 1137. https://doi.org/ $10.3390 /$ polym 13071137

\section{Academic Editors}

Seeram Ramakrishna and Yong Liu

Received: 9 March 2021

Accepted: 31 March 2021

Published: 2 April 2021

Publisher's Note: MDPI stays neutra with regard to jurisdictional claims in published maps and institutional affiliations.

Copyright: (c) 2021 by the authors. Licensee MDPI, Basel, Switzerland. This article is an open access article distributed under the terms and conditions of the Creative Commons Attribution (CC BY) license (https:// creativecommons.org/licenses/by/ $4.0 /)$.

\begin{abstract}
Blends of two long-chain branched polypropylenes (LCB-PP) and five linear polypropylenes (L-PP) were prepared in a single screw extruder at $240^{\circ} \mathrm{C}$. The two LCB-PPs were self-created via reactive extrusion at $180^{\circ} \mathrm{C}$ by using dimyristyl peroxydicarbonate (PODIC C126) and dilauroyl peroxide (LP) as peroxides. For blending two virgin and three recycled PPs like coffee caps, yoghurt cups and buckets with different melt flow rate (MFR) values were used. The influence of using blends was assessed by investigating the rheological (dynamic and extensional rheology) and mechanical properties (tensile test and impact tensile test). The dynamic rheology indicated that the molecular weight as well as the molecular weight distribution could be increased or broadened. Also the melt strength behavior could be improved by using the two peroxide modified LCB-PP blends on the basis of PODIC C126 or PEROXAN LP (dilauroyl peroxide). In addition, the mechanical properties were consistently enhanced or at least kept constant compared to the original material. In particular, the impact tensile strength but also the elongation at break could be increased considerably. This study showed that the blending of LCB-PP can increase the investigated properties and represents a promising option, especially when using recycled PP, which demonstrates a real "up-cycling" process.
\end{abstract}

Keywords: reactive extrusion; long-chain branching; recycled polypropylene; blends; upcycling; rheology; mechanical properties

\section{Introduction}

The worldwide production of plastics has experienced great growth in the last decades and therefore the consumption of plastics has also increased more and more. As such, plastics and their products are already being promoted as the material of the 21st century. The three largest areas in which plastic products play an important role are the packaging industry with $40 \%$, building and construction with $20 \%$, and the automotive industry with $10 \%$. For these and other application segments, the plastics that are used can be divided into different polymers. These include polypropylene (PP), polyethylene (PE), polyvinyl carbonate (PVC), polystyrene (PS), polyethylene terephthalate (PET) and others [1].

Isotactic polypropylene (PP) is one of the most popular and most universally applicable plastics worldwide with one of the largest share in global plastic production next to polyethylene (PE) [1]. PP is used in a wide range of applications from plastic pipes to various packaging applications and injection molding. Due to its excellent properties, such as good mechanical properties, high melting temperature, high chemical resistance or low density, PP is used in the aforementioned applications [2]. In general, the recycling of plastics and thus also of PP is becoming increasingly important due to the enormous production and consumption of plastics. In the literature there are different approaches for the solution of plastic waste such as mechanical recycling, energy recovery and landfill $[3,4]$. In particular, mechanical recycling is environmentally friendly and represents an 
economically viable practice, where theoretically a saving of $20-50 \%$ of the market price is achieved compared to the virgin material [5-8]. Various methods have been tried out in the literature to promote the quality of the recycled plastic. The basic idea is to add other material during the melting process such as virgin polymers, fillers, fibers, compatibilizers etc. [9-21].

However, the use of linear PP (L-PP) is limited because it has a relatively low melt strength and shows no strain hardening, which is particularly important in processes such as thermoforming, foaming and blow molding [22-24]. According to the literature, the introduction of long chain branching improves the properties of L-PP like a more pronounced shear-thinning effect or strain hardening, which leads to the effect that the melt strength increases significantly [25-30]. There are different methods to produce longchain branched PP (LCB-PP) such as direct synthesis using metallocene catalysis [31,32], electron beam irradiation [33-35] or reactive extrusion [36-40]. Reactive extrusion is the most popular method because it requires no solvents, allows short reaction times and involves relatively low infrastructure costs [41,42]. In addition to the introduction of longchain branching, various concurrent reactions take place in the case of polypropylene during reactive extrusion. Mainly, chain scission ( $\beta$-scission) is expected in the case of PP, which leads to the formation of unsaturated short chain segments as a result $[43,44]$. Due to the use of peroxides, this phenomenon tends to become more common and is known as controlled rheology PP (CR-PP). This leads to a reduction in viscosity and to a reduction in molecular weight as well as a narrowing of the molecular weight distribution $[45,46]$. The use of peroxides can lead to further side reactions during reactive extrusion such as recombination disproportionation of peroxide radicals. The temperature used also plays an important role in reactive extrusion in the case of PP. Higher temperatures lead to $\beta$-scission and disproportionation being favored to some extent, thus negatively affecting the introduction of LCB. For this reason, reactive extrusion is mostly carried out at a temperature of $180{ }^{\circ} \mathrm{C}$, whereas higher temperatures are used in industry and the balance shifts in the direction of chain scission.

Nonetheless, not only can the production of LCB-PP lead to an increase in melt strength. In order to achieve a higher melt strength also the blending with L-PP and LCB-PP is possible to obtain a significant increase of strain hardening. According to Stange et al. [47], a small amount of LCB-PP influences the rheological properties significantly, especially the elongation behavior. The same behavior was concluded by Fang et al. [48], which reported that adding LCB-PP into L-PP improved the melt strength resulting in a strain-hardening behavior. In addition to the rheological properties of L-PP/LCB-PP blends, according to McCallum et al. [49] not only could the melt strength be increased but also the mechanical properties as well. These studies have been carried out mainly with virgin PP materials.

The aim of this work is to investigate the rheological and mechanical properties of blends consisting of PP respective recycled PP and $10 \mathrm{wt}$ \% LCB-PP blended at an extrusion temperature of $240{ }^{\circ} \mathrm{C}$ to simulate industry-related processes. The novel LCB-PPs (based on dimyristyl peroxydicarbonate (PODIC C126) and dilauroyl peroxide (PEROXAN LP)), which were produced by reactive extrusion in a previous study in the research group and investigated for their mechanical and rheological properties, were used as blend material in this work [50]. In order to investigate the blend properties of these two LCB-PP materials as potential masterbatch material, a virgin linear PP but also a commercial available high melt strength polypropylene (HMS-PP) with a content of $10 \mathrm{wt} \%$ were additionally used in this work for better comparison. For the experiments in this study, two different virgin PPs were used, which covered a melt flow rate (MFR) range between 8-21 g/10 min. Besides the virgin material, three different recyclates consisting of flakes from yoghurt cups, coffee caps and buckets were blended with the respective LCB-PPs. To the best of our knowledge, no papers have been published in which recycled PP and their blends with LCB-PP were analyzed. 


\section{Materials and Methods}

\subsection{Materials}

Two different isotactic PP homopolymers were used for the study, which were supplied by Borealis (Vienna, Austria). The type of HD 601CF (PP3; MFR value of $8 \mathrm{~g} / 10 \mathrm{~min}$ at $230{ }^{\circ} \mathrm{C}$ and $2.16 \mathrm{~kg}$ ) is normally used as film resin for chill roll processes and the second virgin PP, HF 700SA (PP4; MFR value of $21 \mathrm{~g} / 10 \mathrm{~min}$ ) can be used for different injection molding applications. Additionally, three different PP were collected from household post-consumer waste, which consisting of flakes from coffee caps (MFR $=14.3 \mathrm{~g} / 10 \mathrm{~min}$ ), which was supplied by Walter Kunststoffe GmbH (Wels, Austria), flakes of yoghurt cups (thermoformed PP; MFR $=5.3 \mathrm{~g} / 10 \mathrm{~min}$ ) and flakes of buckets (injection-molded PP; MFR $=31.9 \mathrm{~g} / 10 \mathrm{~min}$ ). The yoghurt cups and buckets were self-collected.

The LCB-PPs, which were used for the blends, were based on HC 600TF (PP2) appropriated for thermoforming applications, which was also supplied by Borealis (Vienna, Austria), and the peroxides PODIC C126 (dimyristyl peroxydicarbonate; $10 \mathrm{~h}$ half-life time at $48^{\circ} \mathrm{C}$ ) or PEROXAN LP (dilauroyl peroxide; $10 \mathrm{~h}$ half-life time at $61^{\circ} \mathrm{C}$ ) from Pergan $\mathrm{GmbH}$ (Bocholt, Germany). The choice of peroxide content was investigated on the basis of a preliminary study, which examined different concentrations from 10 to $200 \mathrm{mmol} / \mathrm{kg}$ $\mathrm{PP}$ of the respective peroxides on virgin material. An increase in melt stiffness as well as an increase in mechanical properties, tensile strength and impact strength, could be observed [50]. These two modified materials have an MFR value of $7.7 \mathrm{~g} / 10 \mathrm{~min}$ for PODIC $\mathrm{C} 126$ and an MFR value $6.0 \mathrm{~g} / 10 \mathrm{~min}$ for PEROXAN LP at $230{ }^{\circ} \mathrm{C}$ and $2.16 \mathrm{~kg}$ weight. In general, the PP2 with an MFR value of $2.8 \mathrm{~g} / 10$ min was used as blend material in this study to get a better comparison between the blends with L-PP and LCB-PP. In addition, the Daploy ${ }^{\mathrm{TM}}$ WB140HMS from the company Borealis (Vienna, Austria) with an MFR value of $2.1 \mathrm{~g} / 10 \mathrm{~min}$ served as a comparison material of a high melt strength polypropylene (HMS-PP).

\subsection{Sample Preparation}

The two LCB-PPs were produced using a three-zone single-screw extruder, Extron 18-26-1.5, with a screw diameter of $18 \mathrm{~mm}$ and a ratio L/D = 25:1 (Extron Engineering, Ltd., Akaa, Finland). The rotational speed was $70 \mathrm{rpm}$ and the temperature profile for the three independent temperature zones (feeding zone/extrusion zone/die zone) was $165 / 180 / 220^{\circ} \mathrm{C}$. The pure material (PP2) and the respective peroxide (PODIC C126 or PEROXAN LP) with a quantity of $10 \mathrm{wt} . \%$ were mixed directly and added to the extruder.

For this study and the production of the blend, the respective pure materials and the investigated mixing ratios are shown schematically in Figure 1.

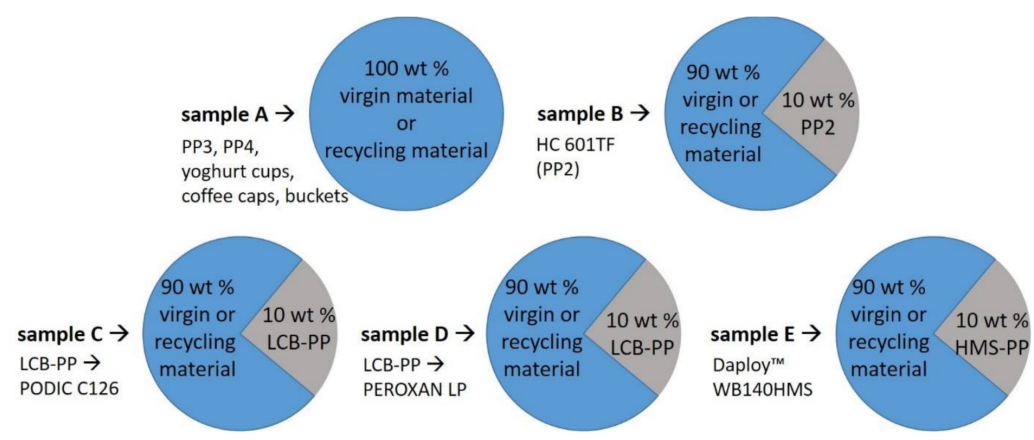

Figure 1. Schematic blend composition and specification of all series.

For better mixing during extrusion (blend production), the three post-consumer waste materials and both LCB-PPs were shredded before use with a universal cutting mill, Pulverisette 19 (Fritsch, Idar-Oberstein, Germany), equipped with a $4 \mathrm{~mm}$ sieve insert. The extrusion or blending of these samples were performed at a temperature profile of 
$165 / 240 / 240{ }^{\circ} \mathrm{C}$ and also a screw rotation of $70 \mathrm{rpm}$. The polymer strands produced were then ground again with the Pulverisette 19 for further production steps.

\subsection{Melt Flow Rate (MFR)}

With a manual testing device from Karg Industritechnik (Krailling, Germany), MeltFlow basic, the MFR measurements were performed in accordance with DIN EN ISO 1133 method A under a load of $2.16 \mathrm{~kg}$ and a temperature of $230^{\circ} \mathrm{C}$ [51].

\subsection{Differential Scanning Caloremtry (DSC)}

The thermal behaviour of all materials (virgin/recycling materials and their blends) after extrusion at $240{ }^{\circ} \mathrm{C}$ was investigated by using TA Q2000 differential scanning calorimeter (DSC) from TA-Instruments (Newcastle, DE, USA). We inserted 5-10 mg of each sample in aluminium pans and the measurements were carried out under a nitrogen atmosphere. The samples were heated from room temperature to $200{ }^{\circ} \mathrm{C}$ at a rate of $10 \mathrm{~K} / \mathrm{min}$, cooled to room temperature and heated a second time also at a rate of $10 \mathrm{~K} / \mathrm{min}$ to $200{ }^{\circ} \mathrm{C}$. The analysis software TA Universal Analysis was used to determine the crystallisation temperature $\left(T_{\mathrm{c}}\right)$ and from the second heating the melting temperature $\left(T_{\mathrm{m}}\right)$ as well as the enthalpy of fusion $\left(\Delta H_{\mathrm{m}}\right)$. From the enthalpy of fusion the degree of cristallinity $\mathrm{Xc}$ was calculated using $207 \mathrm{~J} / \mathrm{g}$ as the enthalpy of a fully crystalline PP.

\subsection{Fourier Transform Infared (FTIR) Measurements}

The Fourier transform infrared (FTIR) spectroscopy measurements were carried out at room temperature with a spectrometer (Tensor 27) of the company Brucker (Billerica, MA, USA), which is equipped with an ATR diamond (DuraSample IR II) with single reflection. The measurement covered with a number of 16 scans and a wave number range of $600-4000 \mathrm{~cm}^{-1}$ with a $4 \mathrm{~cm}^{-1}$ resolution.

\subsection{Rheology Properties}

The characterisation of the polymer melt and its rheological properties was carried out by using dynamic rheology and extensional rheology measurements. The specimens for the dynamic rheology measurements were made by compression molding (Collin $\mathrm{P}$ 200 P, Maitenbeth, Germany) at a temperature of $240{ }^{\circ} \mathrm{C}$ and a pressure of 30 bar. The dimensions for the round samples were $25 \mathrm{~mm}$ in diameter and $1.2 \mathrm{~mm}$ thick. For the extensional rheology measurement stripes with dimensions of $20 \times 8 \mathrm{~mm}$ were necessary, which in form of squares were produced by compression molding with dimensions of $60 \times 60 \times 0.8 \mathrm{~mm}$.

The dynamic rheology respectively the frequency sweep test was done on a plate-plate system with a diameter of $25 \mathrm{~mm}$ via Anton Paar (Graz, Austria) MCR 302 rheometer, which was equipped with a CTD 450 heating chamber, under nitrogen at $230{ }^{\circ} \mathrm{C}$. The frequency range was selected from 628 to $0.01 \mathrm{rad} / \mathrm{s}$, the deformation rate increased logarithmically over the selected range from $1 \%$ to $2 \%$, and the gap size of the plate-plate system was $1 \mathrm{~mm}$. Also the extensional rheology measurements were done at the Anton Paar MCR 302 rheometer, which was equipped with a Sentmanat Extensional Rheometer (SER-HPV 1, Xpansion instruments, Tallmadge, OH, USA). Three different strain rates $\left(\dot{\varepsilon}=5 ; 1 ; 0.1 \mathrm{~s}^{-1}\right)$ were used at a temperature of $180^{\circ} \mathrm{C}$ and additionally the corresponding start up curves were measured with a plate-plate system with a diameter of $25 \mathrm{~mm}$ at 0.001 and $0.1 \mathrm{~s}^{-1}$ shear rates.

\subsection{Mechanical Properties}

Tensile and tensile impact strength tests were used for the determination of the mechanical properties. The required test specimens were produced using Haake Mini Lab II (Thermo Fisher, Waltham, MA, USA), a twin screw extruder, in combination with Haake Mini Jet II injection molding equipment from Thermo Fisher Scientific (Waltham, MA, USA). The extrusion was carried out at a temperature of $240^{\circ} \mathrm{C}$ and a screw rotation 
of $100 \mathrm{rpm}$. For the injection molding process, the mold temperature was set at $90{ }^{\circ} \mathrm{C}$, the pressure was 350 bar with an injection time of $10 \mathrm{~s}$.

The test machine for the tensile test (Zwick 050, ZwickRoell GmbH and Co. KG, Ulm, Germany) was used with a test speed of $10 \mathrm{~mm} / \mathrm{min}$ and was equipped with a $1 \mathrm{kN}$ load cell and an extensometer. The test specimens for these measurements corresponded to the standard ISO 527-2-5A [52].

For the tensile impact strength test the specimens were notched on both sides with a Notch-Vis from Ceast and tested according to ISO 8256/1A [53] on an Instron Ceast 9050 (2 J hammer; cross head mass $=15 \mathrm{~g}$, Instron, Darmstadt, Germany).

\subsection{Scanning Electron Microscopy (SEM)}

For the morphological investigation of the respective samples, the fracture surfaces of the impact tensile test samples were analyzed using scanning electron microscopy (FEI Philips XL30, Hillsboro, OR, USA). The individual samples were coated with gold prior to imaging (Agar Sputter Coater B7340, Stansted, UK).

\section{Results}

\subsection{Melt Flow Rate}

In general, the MFR value gives a first good approximation of melt behavior and the process ability of polymer blends. It is generally known that the MFR value, especially for $\mathrm{PP}$, can increase very strongly as a result of $\beta$-scission and the associated increase in chain mobility, but can also be reduced by long chain branching or cross-linking [54-56].

Figure 2a shows the MFR values of the blending materials, which amounted for PP2 $=2.8 \mathrm{~g} / 10 \mathrm{~min}$, LCB-PP modified by PODIC C126 $=7.7 \mathrm{~g} / 10 \mathrm{~min}$, LCB-PP modified by PEROXAN LP $=6.0 \mathrm{~g} / 10 \mathrm{~min}$. Figure $2 \mathrm{~b}$ represents the MFR values of all materials after the extrusion temperature of $240{ }^{\circ} \mathrm{C}$. It can be clearly seen that the use of blends reduces the MFR values. In particular, for the starting materials with a high MFR value such as PP4 (virgin granulate) but also for the flakes or bucket a reduction is visible. For the two materials with a lower MFR value (PP3 and cups) a slight reduction or at least keeping the values constant can be observed. However, as these values do not increase due to the addition of LCB-PP, which show a higher MFR than cups, it can be assumed that the mixing rule is not the reason for the reduction of the MFR values.

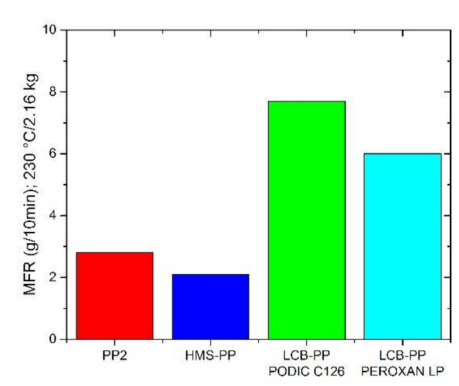

(a)

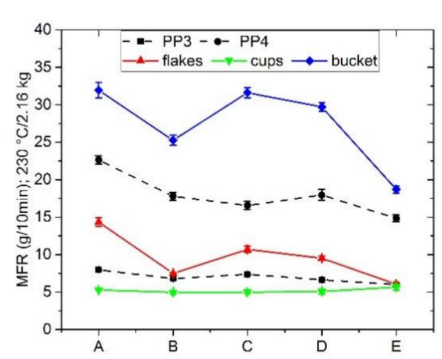

(b)

Figure 2. Melt flow rate (MFR) values of the materials, which was used for blending (a) as well as all starting materials and their blend series (b); measured at $230{ }^{\circ} \mathrm{C}$ with $2.16 \mathrm{~kg}$.

\subsection{Dynamic Rheology Properties}

Rheology measurements have been shown in literature to be a good tool of identifying molecular structures and to be very sensitive to changes in them [36,57-64]. Several studies have investigated the rheological behavior of blends with linear PP and branched PP or PE and have shown that these blends have a higher shear thinning effect or strain hardening compared to linear PP [47-49,65]. The Figure 3 show the viscosity curves, which were measured at $230{ }^{\circ} \mathrm{C}$ to achieve better comparability with the MFR values, of the respective virgin materials and the blends. The viscosity curves of the respective materials are very 
close to each other, so these curves were additionally plotted larger in the low shear range in order to get a better overview. For the series with lower MFR (PP3, flakes and cups) it was found that the use of LCB-PPs or HMS-PP resulted in a pronounced increase in viscosity. While the blends with L-PP only achieved a slight increase in viscosity for the recycled materials, the curve progression of virgin granules could only be kept constant. No clear trends could be observed for the two series with higher MFR (PP4 and buckets). On the one hand, no changes between the individual viscosity curves are clearly visible in the PP4 series blends and on the other hand, an opposite trend could be observed in the recycled bucket and its blends compared to the other recyclates. In this case, the blend with L-PP shows an increase in the viscosity curve, whereas the blends with LCB-PPs and HMS-PP show a small reduction.

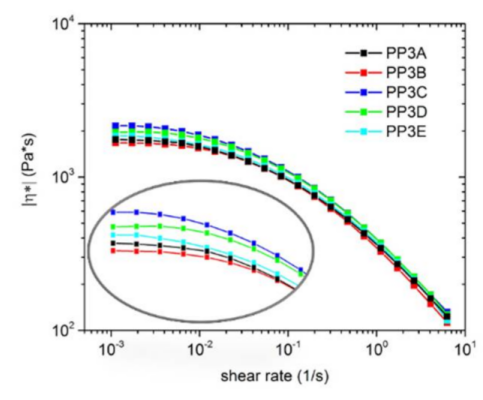

(a)

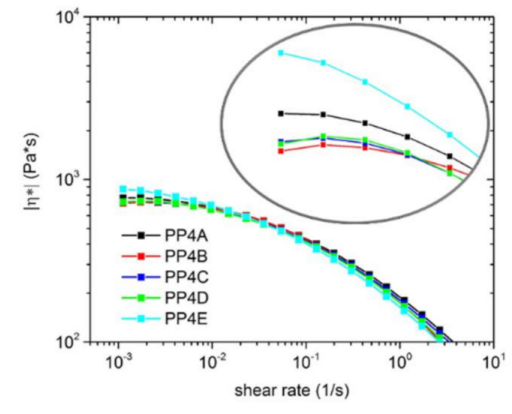

(b)

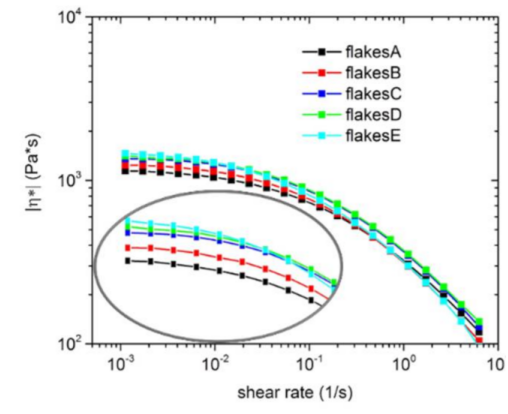

(c)

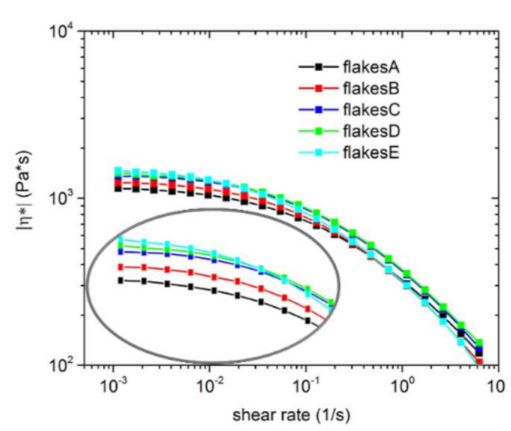

(d)

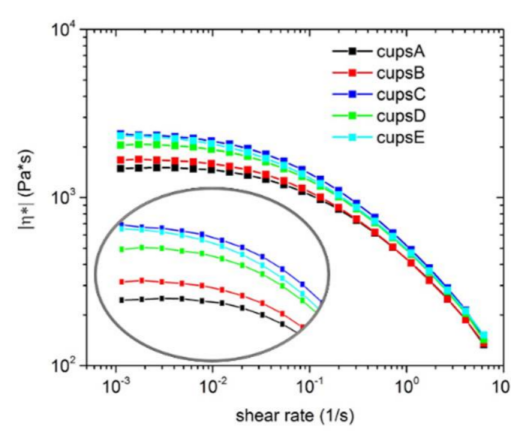

(e)

Figure 3. Complex viscosity of all samples (polypropylenes PP3 (a) and PP4 (b), flakes (c), cups (d), bucket (e)) and their blends; measured at $230{ }^{\circ} \mathrm{C}$.

In addition to the complex viscosity, the storage modulus $\left(G^{\prime}\right)$ and the loss modulus $\left(G^{\prime \prime}\right)$ are important parameters in dynamic rheology, which provide information about viscous or elastic effects depending on the shear rate [66,67]. In Figures 4 and 5 the respective curves of the associated series are shown. For a better representation of the crossover points, this area of the curves was displayed larger and additionally the intersection points were marked with a star for each graph. Figure 4 shows the curves of the two virgin materials PP3 (a) and PP4 (b) and their blends. If both pictures are compared, it becomes clear that the curves and the cross points of $G^{\prime}$ and $G^{\prime \prime}$ are shifted from PP4 to higher frequencies, which is attributable to the high MFR values. As the curves are so close to each other in nearly all cases and the crossing point of $G^{\prime}$ and $G^{\prime \prime}$ partly overlap, the respective values are given in Table 1. 


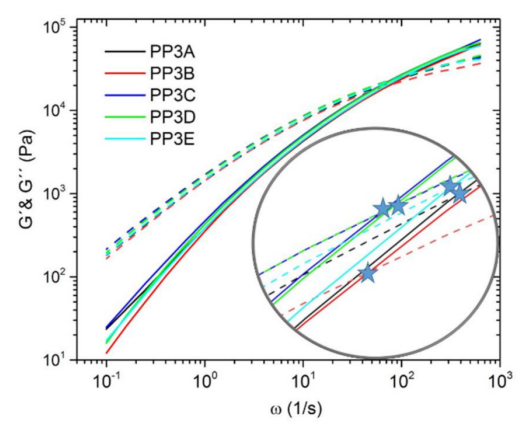

(a)

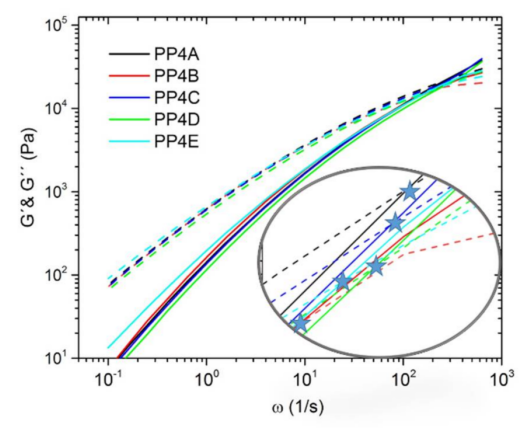

(b)

Figure 4. Storage modulus $\left(G^{\prime}\right)$ lines and loss modulus $\left(G^{\prime \prime}\right)$ dashed lines of the series PP3 (a) and PP4 (b) and their blends; the stars represent the crossover point of the two curves ( $G^{\prime}$ and $\left.G^{\prime \prime}\right)$ of the respective blend series; measured at $230^{\circ} \mathrm{C}$.

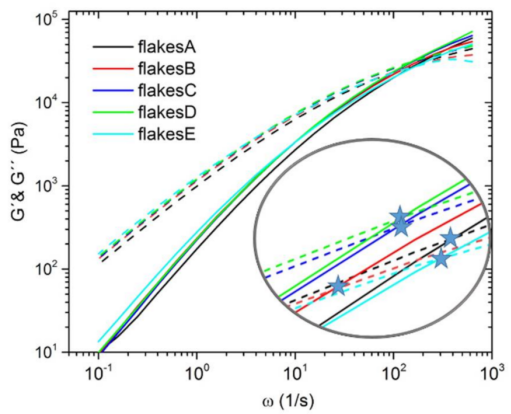

(a)

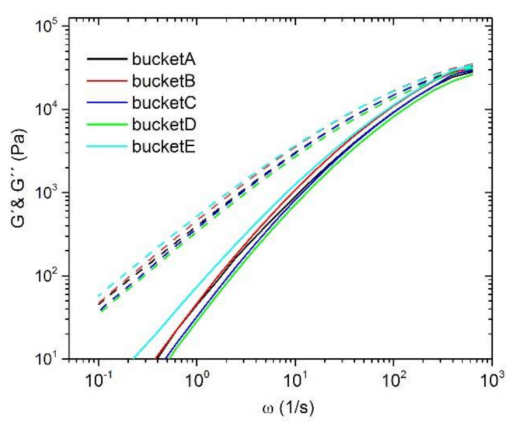

(c)

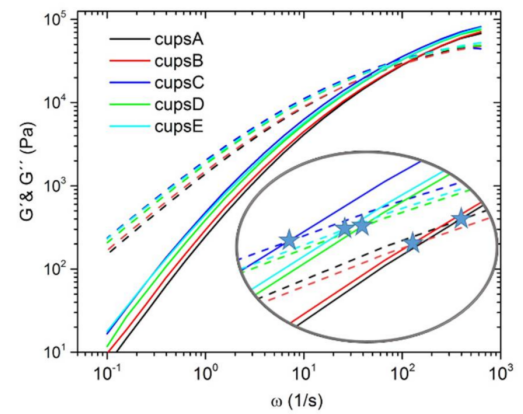

(b)

Figure 5. Storage modulus $\left(G^{\prime}\right)$ lines and loss modulus $\left(G^{\prime \prime}\right)$ dashed lines of the flakes (a), cups (b), bucket (c) and their blends; the stars represent the crossover point of the two curves $\left(G^{\prime}\right.$ and $\left.G^{\prime \prime}\right)$ of the respective blend series; measured at $230{ }^{\circ} \mathrm{C}$.

Figure 5 additionally shows the series of recyclates (flakes (a), cups (b) and bucket (c)). Comparing the different recyclates with each other, the difference between the crossing points of $G^{\prime}$ and $G^{\prime \prime}$ is even more pronounced. It can be seen that with increasing MFR value the crossing point shifts to higher frequencies. This is most pronounced with the bucket. Here no intersection point could be determined under the given measurement conditions because it was outside the measurement range. However, the values of the crossing points of the other two series (flakes and cups) are also listed additionally in Table 1. 
Table 1. Results of crossover point $\left(\mathrm{G}^{\prime}=\mathrm{G}^{\prime \prime}\right)$ from dynamic rheological measurements at $230{ }^{\circ} \mathrm{C}$.

\begin{tabular}{cccc}
\hline Sample & $\omega_{\mathbf{C}}(\mathbf{r a d} / \mathbf{s})$ & $G_{\mathbf{C}}(\mathbf{k P a})$ & Mw/MMD \\
\hline PP3A & 102 & 24.52 & \\
PP3B & 78 & 20.26 & $M w \uparrow, M M D \uparrow$ \\
PP3C & 80 & 23.51 & $M w \uparrow, M M D \uparrow$ \\
PP3D & 81 & 22.96 & $M w \uparrow, M M D \uparrow$ \\
PP3E & 100 & 24.09 & $M w \uparrow, M M D \uparrow$ \\
\hline PP4A & 255 & 21.18 & \\
PP4B & 170 & 15.29 & $M w \uparrow, M M D \uparrow$ \\
PP4C & 238 & 19.37 & $M w \uparrow, M M D \uparrow$ \\
PP4D & 232 & 18.87 & $M w \uparrow, M M D \uparrow$ \\
PP4E & 201 & 16.96 & $M w \uparrow, M M D \uparrow$ \\
\hline FlakesA & 177 & 32.47 & $M w \uparrow, M M D \uparrow$ \\
FlakesB & 124 & 25.02 & $M w \uparrow, M M D \uparrow$ \\
FlakesC & 150 & 30.16 & $M w \uparrow, M M D \uparrow$ \\
FlakesD & 152 & 31.01 & $M w \uparrow, M M D \uparrow$ \\
FlakesE & 170 & 27.47 & \\
\hline cupsA & 123 & 31.86 & $M w \uparrow, M M D \uparrow$ \\
cupsB & 106 & 29.61 & $M w \uparrow, M M D \uparrow$ \\
cupsC & 76 & 30.00 & $M w \uparrow, M M D \uparrow$ \\
cupsD & 93 & 31.22 & $M w \uparrow, M M D \uparrow$ \\
cupsE & 90 & 31.14 & \\
\hline
\end{tabular}

The position or change of the crossover point can be used to determine the change in molecular weight $\left(M_{\mathrm{W}}\right)$ or molecular weight distribution (MMD) [68-73]. If the crossover point shifts to lower frequencies, this represents the presence of branched molecules with longer relaxation time. In contrast, the vertical shift of the crossover point to lower $G$ values results from a broadening of the MMD. The values of the crossover frequency $\omega_{\mathrm{C}}$ and crossover modulus $G_{C}$ are given in Table 1. By comparing the individual series and their blends with each other, it can be seen that both the $\omega_{C}$ values and the $G_{C}$ values are lower than the virgin/recycled material used. All in all, this could mean that the use of blends, which have been applied in this work, can increase the molecular weight and broaden the molecular weight distribution compared to the respective starting materials.

\subsection{Extensional Rheology}

It is known that extensional rheology plays an important role in the detection of long-chain branching and the associated changes in molecular structure [74-77]. It has been shown in various studies that the melt strength, which is also referred to as strain hardening, can be increased compared to linear PP [78-82]. The increased melt strength of materials is very important and desired for many manufacturing processes such as thermoforming, film casting, film blowing, foaming, and so on $[83,84]$.

The following figures show the starting materials and the respective blends using PP2, the two LCB-PPs and HMS-PP. The dashed lines correspond to the linear viscoelastic start-up curve (LVE), which was measured by shear rheology and multiplied by the Trouton factor to obtain the extensional viscosity [85]. The presence or absence of melt strength (strain hardening) of all materials were measured with three different Hencky strain rates $\left(\dot{\varepsilon}=5 ; 1 ; 0.1 \mathrm{~s}^{-1}\right)$. As expected, the virgin materials showed no deviation of the respective strain curves from the LVE and thus no strain hardening could be determined in all cases (Figure 6a). The same result was reflected in the blends with a content of $10 \mathrm{wt} . \%$ PP2, which is represented in Figure 6b. Again, no deviation and thus no strain hardening could be achieved. In contrast, the two blends with the respective LCB-PPs and HMS-PP showed a significant deviation from the LVE curve for all three different strain rates. In these cases, a significant strain hardening and associated increased melt strength behavior can be seen for the LCB-PP with PODIC C126 in Figure 7a, for LCB-PP with PEROXAN LP in Figure 7c and for HMS-PP in Figure 7e. 


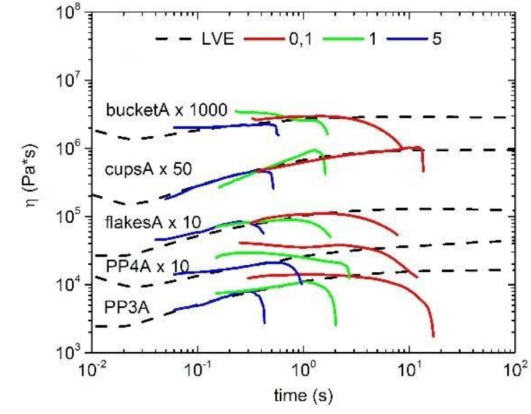

(a)

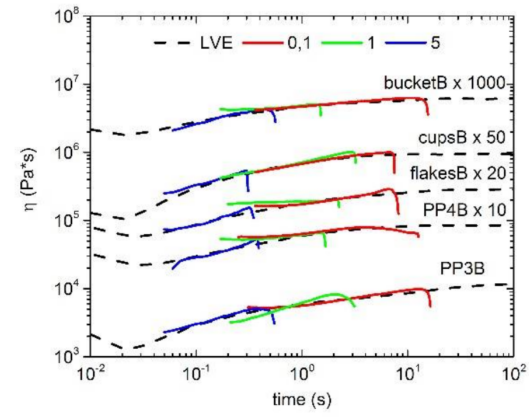

(b)

Figure 6. Extensional rheology of all curves for the virgin materials (a) and with the PP2 blends series (b).

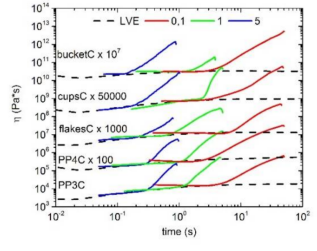

(a)

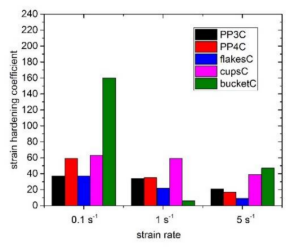

(b)

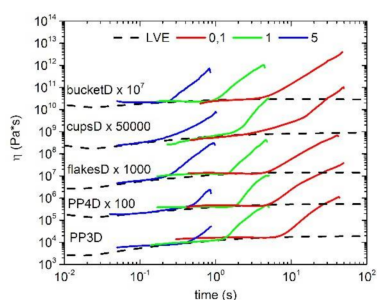

(c)

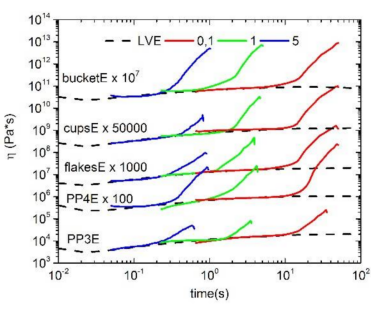

(e)

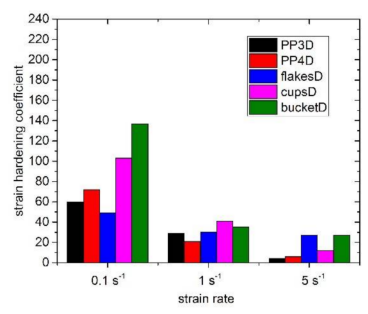

(d)

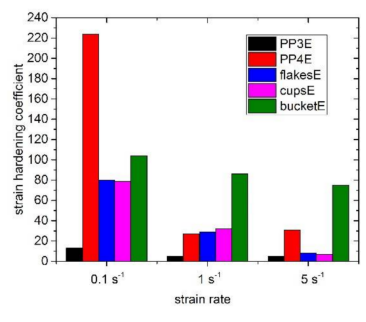

(f)

Figure 7. Extensional rheology curves of all samples with the blend series of long-chain branched polypropylene (LCB-PP) dimyristyl peroxydicarbonate (PODIC C 126) (a), with LCB-PP dilauroyl peroxide (PEROXAN LP) (c) and HMS-PP (e); Strain Hardening Coefficient of all samples with the blend series of LCB-PP PODIC C 126 (b), with LCB-PP PEROXAN LP (d) and HMS-PP (f).

In order to make a better statement or distinction about the strain hardening behavior and thus the melt strength of the blends with the two LCB-PPs and HMS-PP, the strain hardening coefficient $(\mathrm{SH})$ of the respective blends was determined. This represents the maximum strain viscosity $\eta(t)$ at the strain hardening rate in relation to the strain viscosity of the LVE curve $\eta_{0}(t)$. The results are represented in Figure $7 b, d, f$. It can generally be seen that with increasing strain rate, the strain hardening coefficient continuously decreases for both blended sets. Comparing the two blend sets with each other, no general statement can be made about the results with PODIC C126 or PEROXAN LP. However, this is clear evidence that the use of LCB-PPs produced by ourselves in laboratory scale as blends can successfully increase melt strength (Figure $7 \mathrm{~b}$ ). Especially with recycled materials, a significant increase in melt strength was observed when using PEROXAN LP LCB-PP (Figure 7d). Here the strain hardening coefficient tends to be higher than the values of the virgin material (PP3 and PP4). In order to be able to make a better statement about the two LCB-PPs, the melt strength of the blends with HMS-PP and their strain hardening coefficients were also investigated (Figure 7f). On the one hand, the same trend was observed again, that the melt strength of the respective series decreased with increasing strain rate and, on the other hand, that the blends with LCB-PPs, with the exception of PP4 and a strain rate of $0.1 \mathrm{~s}^{-1}$, can keep up with the blends with HMS-PP in terms of melt stiffness. 
All in all, the melt strength properties of the relevant samples, especially those of the recycled materials, can be increased and thus new areas of application can be found.

\subsection{Thermal Characterization}

All materials, including the complete mixtures of the different blends, exhibit single melting and crystallization peaks. The temperature of melting $(T \mathrm{~m})$ and crystallization $(T \mathrm{c})$ as well as the crystallinity of all blends and their virgin material are listed in the Table 2. To determine the crystallinity, the melting curves were integrated from $80^{\circ} \mathrm{C}$ to the temperature of return to baseline after melting (The diagrams of the second heating are presented in Figure S1 in the Supplementary Material). Except for the buckets which consist of a PP copolymer and has a much broader melting peak with lower peak temperature. In that case the integration starts at $50{ }^{\circ} \mathrm{C}$. Regarding the crystallization temperature there is no clear trend visible, in most cases there is no strong shift by the addition of PP2 and the LCB-PPs. The same behavior was reported from Tabatabaei et al. [86] for blends containing $10 \mathrm{wt} . \%$ LCB-PP and more. Adding of HMS-PP results in every series in the highest crystallization temperature, which indicates a nucleating effect. This is also visible by a slight increase in crystallinity for the mixtures of PP3, PP4, flakes and cups with HMS-PP. The blends from the buckets show a different behavior, there occurred a notable increase of the crystallization temperature if the second components are added. This is not unlikely if primarily homopolymer type PP is added to a PP copolymer. Interestingly, the blends of the bucket with the LCB-PPs show a $10 \%$ increase of crystallinity. It should be respected that the melting curves of PP3C, PP4A-D and flakesC and E contain a small shoulder at a temperature between $149-152{ }^{\circ} \mathrm{C}$, which it the typical melting temperature of the $\beta$ - phase of PP. In principle this should be considered if someone calculates the crystallinity from melting curves because a superposition of melting of the $\beta$-phase and recrystallization to the $\alpha$-phase takes place. But this shoulder is really small and the calculated crystallinities do not show outliers, so it can be neglected.

Table 2. Crystallization temperature $\left(T_{\mathrm{c}}\right)$, melting temperature and crystallinity (2nd heating) of all samples obtained from differential scanning calorimetry (DSC) measurements; mechanical properties (tensile modulus, elongation at break and tensile strength) obtained from tensile test.

\begin{tabular}{ccccccc}
\hline Sample & $\boldsymbol{T}_{\mathbf{c}}\left({ }^{\circ} \mathbf{C}\right)$ & $\boldsymbol{T}_{\mathbf{m}}\left({ }^{\circ} \mathbf{C}\right)$ & $\boldsymbol{X}_{\mathbf{C}}(\mathbf{\%})$ & $\boldsymbol{E}_{\mathbf{t}}(\mathbf{M P a})$ & $\boldsymbol{\varepsilon}_{\mathbf{B}}(\mathbf{\%})$ & $\left.\sigma_{\mathbf{m}} \mathbf{( M P a}\right)$ \\
\hline PP3A & 115 & 167 & 50 & $2039 \pm 139$ & $689 \pm 65$ & $38.7 \pm 0.5$ \\
PP3B & 119 & 169 & 49 & $1848 \pm 115$ & $650 \pm 105$ & $36.5 \pm 0.7$ \\
PP3C & 121 & 167 & 50 & $2181 \pm 140$ & $921 \pm 77$ & $38.9 \pm 0.3$ \\
PP3D & 115 & 165 & 50 & $1904 \pm 108$ & $1008 \pm 34$ & $38.1 \pm 0.5$ \\
PP3E & 129 & 168 & 53 & $2037 \pm 81$ & $681 \pm 57$ & $36.9 \pm 0.3$ \\
\hline PP4A & 118 & 164 & 50 & $1960 \pm 18$ & $23 \pm 4$ & $37.1 \pm 0.5$ \\
PP4B & 118 & 164 & 48 & $1898 \pm 151$ & $35 \pm 4$ & $37.0 \pm 0.5$ \\
PP4C & 120 & 165 & 50 & $1980 \pm 164$ & $77 \pm 25$ & $36.9 \pm 0.3$ \\
PP4D & 117 & 165 & 50 & $1950 \pm 125$ & $26 \pm 6$ & $36.7 \pm 0.7$ \\
PP4E & 128 & 167 & 50 & $1966 \pm 53$ & $43 \pm 5$ & $36.8 \pm 0.4$ \\
\hline FlakesA & 121 & 167 & 42 & $1864 \pm 55$ & $748 \pm 85$ & $32.8 \pm 0.6$ \\
FlakesB & 121 & 165 & 43 & $1436 \pm 35$ & $863 \pm 48$ & $29.8 \pm 0.4$ \\
FlakesC & 122 & 165 & 44 & $1717 \pm 51$ & $917 \pm 38$ & $31.7 \pm 0.2$ \\
FlakesD & 121 & 165 & 44 & $1733 \pm 66$ & $916 \pm 49$ & $32.2 \pm 0.3$ \\
FlakesE & 125 & 166 & 45 & $1502 \pm 123$ & $912 \pm 21$ & $30.5 \pm 0.4$ \\
\hline cupsA & 129 & 167 & 51 & $1794 \pm 143$ & $859 \pm 39$ & $37.1 \pm 0.3$ \\
cupsB & 129 & 167 & 50 & $1913 \pm 188$ & $758 \pm 35$ & $37.5 \pm 0.4$ \\
cupsC & 129 & 167 & 50 & $1708 \pm 123$ & $913 \pm 32$ & $36.9 \pm 0.4$ \\
cupsD & 129 & 167 & 51 & $1818 \pm 114$ & $826 \pm 29$ & $37.1 \pm 0.2$ \\
cupsE & 130 & 167 & 52 & $1976 \pm 188$ & $757 \pm 48$ & $37.9 \pm 0.3$ \\
\hline
\end{tabular}


Table 2. Cont.

\begin{tabular}{rcccccc}
\hline Sample & $\boldsymbol{T}_{\mathbf{c}}\left({ }^{\circ} \mathbf{C}\right)$ & $\boldsymbol{T}_{\mathbf{m}}\left({ }^{\circ} \mathbf{C}\right)$ & $\boldsymbol{X}_{\mathbf{C}}(\mathbf{\%})$ & $\boldsymbol{E}_{\mathbf{t}}(\mathbf{M P a})$ & $\boldsymbol{\varepsilon}_{\mathbf{B}}(\mathbf{\%})$ & $\sigma_{\mathbf{m}}(\mathbf{M P a})$ \\
\hline bucketA & 114 & 151 & 42 & $1570 \pm 94$ & $892 \pm 73$ & $30.9 \pm 1.3$ \\
bucketB & 114 & 155 & 44 & $1537 \pm 75$ & $813 \pm 129$ & $32.8 \pm 0.5$ \\
bucketC & 114 & 154 & 54 & $1488 \pm 81$ & $880 \pm 134$ & $30.9 \pm 1.1$ \\
bucketD & 114 & 153 & 54 & $1560 \pm 70$ & $864 \pm 67$ & $30.4 \pm 1.3$ \\
bucketE & 124 & 157 & 45 & $1476 \pm 50$ & $817 \pm 69$ & $30.6 \pm 1.4$ \\
\hline
\end{tabular}

\subsection{Mechanical Properties}

The determination of mechanical properties of each material consists of tensile and tensile impact strength test, whereby both tests are good methods to analyze the material properties in dynamic and quasi-static loading. In particular, the tensile test and its data like modulus of elasticity, elongation at break and tensile strength gives a good insight into the general deformation behavior of polymers and, therefore, allows general statements to be made about the influence of material modification [87-89]. Figure 8 illustrates the stress-strain curves for all materials, which were obtained from tensile test.

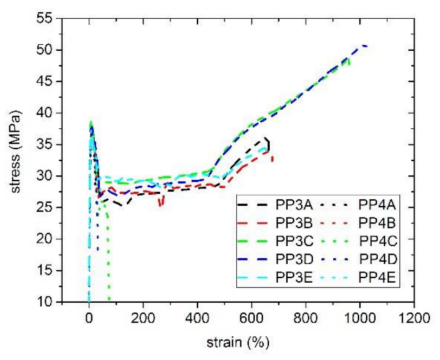

(a)

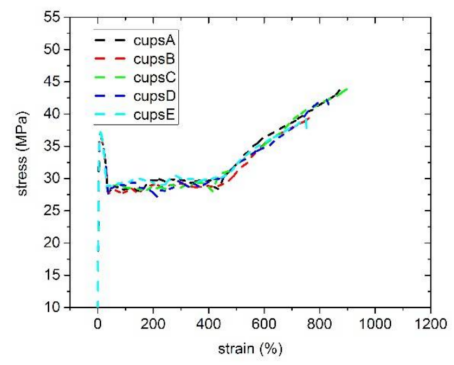

(c)

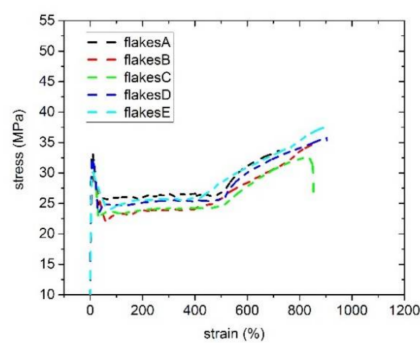

(b)

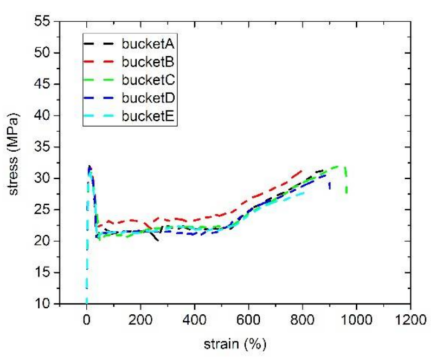

(d)

Figure 8. Stress-strain curves of all samples (PP3 and PP4 (a), flakes (b), cups (c), bucket (d)) obtained from tensile test.

Additionally, Table 2 displays the tensile properties, including the tensile modulus $\left(E_{\mathrm{t}}\right)$, the elongation at break $\left(\varepsilon_{\mathrm{B}}\right)$ and the tensile strength $\left(\sigma_{\mathrm{m}}\right)$. It could be observed, that the tensile strength, which is defined as first maximum of the stress-strain curve according ISO 527-1, was kept constant for all blends compared to their virgin materials [52]. Also, the observation of the tensile modulus did not show any significant change and the values are constant within a certain range. However, the elongation at break showed a change as a result of the use of blends. It was found that the sets of blends consisting LCB-PP had an increase and at least a constant level in comparison to the virgin materials. For example, the values of PP3 increased by $33 \%$ and $46 \%$, respectively, through the blending with LCB-PP, but also a significant increase of $23 \%$ was achieved with the recycled flakes.

The results of the tensile impact strength test are shown in Figure 9. Here it can be clearly seen that the use of blends leads to an increase in impact tensile strength. An increase can be seen in the blending with a pure material (PP2), with the exception of PP3, as well as in the use of LCB-PP. In addition, it is evident that the addition of LCB-PP can further increase the results. This is especially the case for the materials of PP3, flakes 
and cups, whereby the LCB-PPs modified with PEROXAN LP are even more pronounced than the respective blends. The respective series with HMS-PP blends also showed an improvement in impact strength compared to the starting materials. However, if we compare the blends of the two LCB-PPs and the HMS-PP with each other, we see that the values are almost constant for the series with PP4 and bucket. However, for the materials with the lower MFR values (PP3, flakes and cups), the LCB-PPs show an increase compared to the HMS-PP. In particular, the blends with LCB-PP, which were modified with PEROXAN LP, are outstanding.

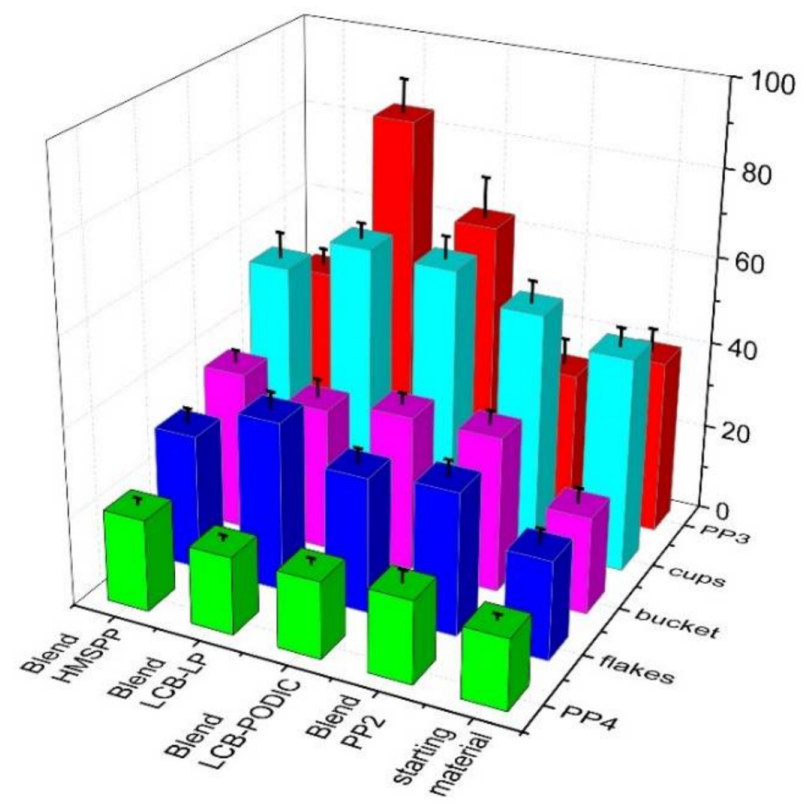

Figure 9. Tensile impact test of all samples.

\subsection{Scanning Electron Microscopy (SEM)}

In addition to the previous results, the mixing behavior of the respective starting materials and the corresponding blends was analyzed using scanning electron microscopy (SEM, Figure 10). For this purpose, the fracture surfaces of the specimens resulting from the impact tensile test were examined. The following pictures show examples of the virgin material PP3 and the blends with PP2, PP-LCB (PODIC C126 and PEROXAN LP) as well as HMS-PP and, for comparison, the recycled flakes of the coffee caps and their corresponding blends.

If a view is taken of the virgin material PP3A and its blends (PP3B-PP3E), no representative difference can be seen between the individual images of the respective morphology. Therefore, it can be assumed that the materials used for the blends in this quantity (10 wt.\%) do not influence the morphological structure and thus the miscibility of the blend is guaranteed. This reflects the results of the DSC measurements which have already been described.

In addition, PP3 and the flakes of the recycled coffee caps have almost the same MFR value, which makes it possible to compare the two materials very well.

A morphological difference between the two starting materials PP3 and flakes of coffee caps can be seen clearly. It can be observed that the recycled post-consumer material (flakesA) already has some polymeric particles in the fracture surface. However, no changes could be detected through the blending process with L-PP (flakesB), LCB-PP on basis of PODIC C126 (flakesC), LCB-PP on basis of PEROXAN LP (flakesD) or HMS-PP (flakesE). This means that no additional particle formation in the morphological structure was recognizable and therefore the blends used did not play a role in the miscibility of the recycled material. This in turn means that there is no phase segregation at the $10 \mathrm{wt} . \%$ blend content used and it is, therefore, very easy to process. 

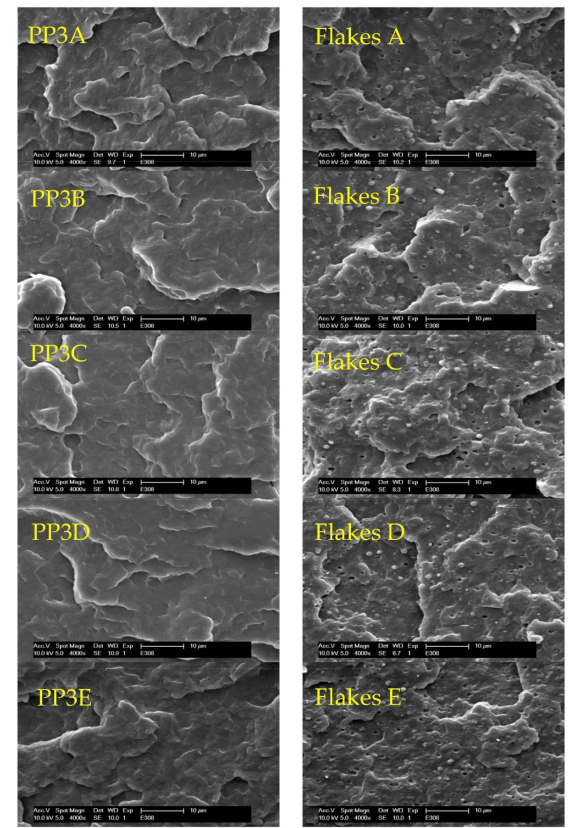

Figure 10. Scanning electron microscope (SEM) images of the virgin material of PP3 and the recycled flakes (A) and the blend series on basis of PP2 (B), LCB-PP with PODIC C126 (C), LCB-PP with PEROXAN LP (D), HMS-PP (E).

These results, which were just described for the two materials at PP3 as well as for the recycled flakes of the coffee caps, were also evident for the other materials. Although there was a large difference in the MFR values between PP4 or the flakes of the recycled buckets and the respective blended materials, no phase segregation was observed here either. These studies of the starting materials with pure PP4, recycled flakes of yoghurt cups and recycled flakes of the bucket and their different blends are shown in Figure A1.

\subsection{Characterization of Modified Polymers Long-Chain Branched Polypropylenes (LCB-PP)}

The branching mechanism of PODIC C126 and PEROXAN LP was examined by using FTIR. It is well known in the literature that the modification or branching with different components such as HDDA (1,6-hexanediol diacrylate) or MAH (maleic anhydride) by using FTIR can be demonstrated clearly $[37,59,90,91]$. Figure 11 shows the FTIR spectra of the unmodified PP and the two LCB-PPs each modified with $10 \mathrm{wt} . \%$ peroxide. The two modified PPs show an absorption band at $1743 \mathrm{~cm}^{-1}$ compared to the unmodified PP. This band describes the stretching vibration of a carbonyl group of an ester, which is generated by the introduction of long-chain branching and the use of peroxides $[25,92,93]$.
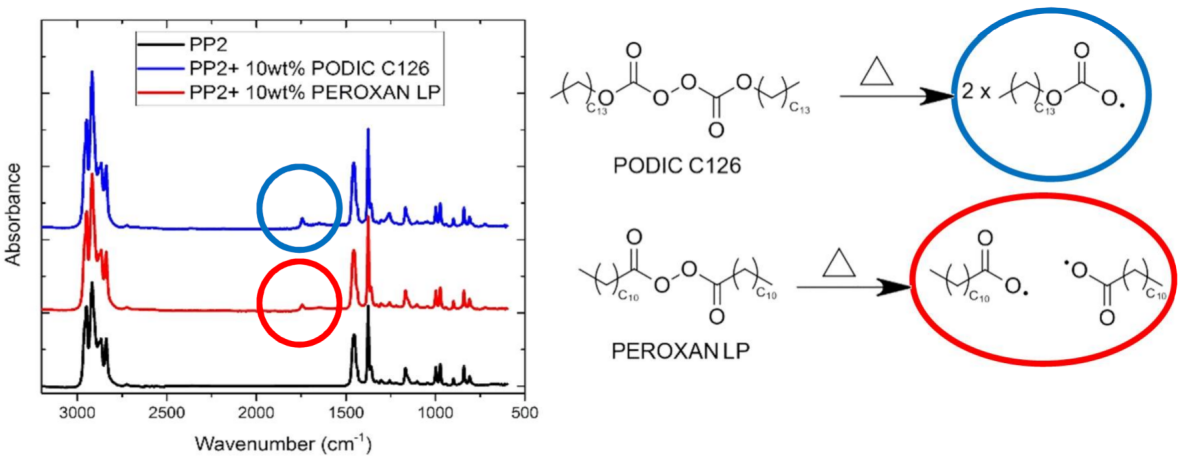

Figure 11. Fourier transform infrared (FTIR) spectra of the unmodified PP and the two LCB-PPs.

To characterize whether the long-chain branches of the LCB-PPs based on PODIC C126 and PEROXAN LP are still present after blending at an extrusion temperature of $240{ }^{\circ} \mathrm{C}$, 
the FTIR spectra of the respective materials (virgin/recycled materials) were additionally examined. The spectra of the blends with $10 \mathrm{wt} . \%$ LCB-PP are shown in the Figure 12. As shown in Figure 11, the characteristic band at $1743 \mathrm{~cm}^{-1}$ for the decomposition products of the peroxides could be detected by introducing the long chain branches. This band can be shown for LCB-PP based on PODIC C126 in Figure 12a and for LCB-PP based on PEROXAN LP in Figure 12b after blending with the respective virgin/recycled materials. This finally supports the statement that the LCB-PP blends can be processed very well at an extrusion temperature of $240{ }^{\circ} \mathrm{C}$ with virgin/recycled material, since on the one hand the long chain branching can be detected in the FTIR and on the other hand the LCB-PP blends, show no impurities at the molecular level as already indicated by the SEM results.

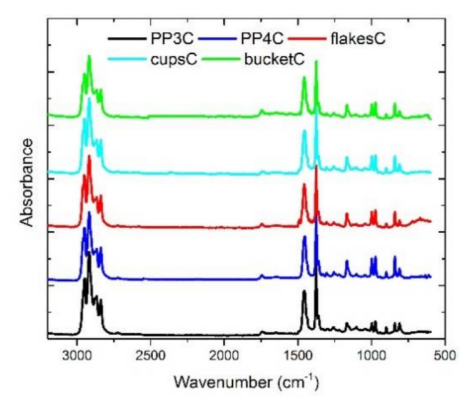

(a)

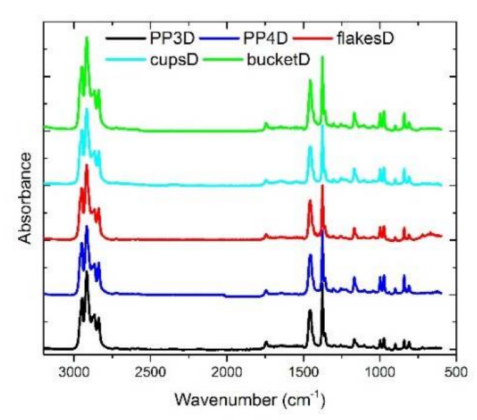

(b)

Figure 12. FTIR spectra of the blend series with LCB-PP (a) on basis of PODIC C126 and (b) on the basis of PEROXAN LP.

\section{Conclusions}

In this study, the influence of blends on virgin PP (HD 601CF and HF 700SA) and recycled PP (flakes of yoghurt cups, coffee caps and buckets) was investigated. For this purpose, two LCB-PPs were used, which were produced and investigated in a previous work in the research group. The two LCB-PPs were prepared by reactive extrusion and by using $10 \mathrm{wt} . \%$ peroxides (PODIC C126 and PEROXAN LP) and served as masterbatches in this work. To investigate the influence of these a virgin blend material, a linear PP (HC $600 \mathrm{TF}$ ) and a commercially available HMS-PP (Daploy ${ }^{\mathrm{TM}}$ WB140HMS) were also used as blend materials. The blends each contained $10 \mathrm{wt} . \%$ of the second component.

The starting materials that were investigated and blended had different initial MFR values ranging from $5 \mathrm{~g} / 10 \mathrm{~min}$ to an MFR of $32 \mathrm{~g} / 10 \mathrm{~min}$, thus covering a wide range of different PPs. By using the respective second blend components, a reduction or at least a constant MFR value could be achieved. In general, the starting materials with higher MFR values, such as the recycled buckets or recycled flakes, but also the vrigin PP (HF 700SA), showed a greater reduction of the MFR value than the starting materials with lower MFR values.

The rheology measurements were carried out at $230{ }^{\circ} \mathrm{C}$ to obtain a better comparison of the complex viscosity versus the MFR values. The series, using virgin PPs, showed different curves of complex viscosity. In the case of $\mathrm{HD} 601 \mathrm{CF}$, the addition of the two LCB PPs and the commercial HMS PP led to an increase in viscosity in the low-frequency range, whereas the linear PP as blending material led to a decrease. In the series, using HF 700 SA, the curves are so close together that no significant change in viscosity can be assumed. Also in the series with the different recycled materials, no uniform trend could be observed. For the series of the flakes of yoghurt cups and coffee caps the same trend was seen by the use of the different blend components. It led in both cases to an increase in viscosity compared to the starting materials. In the case of the flakes of the bucket, again, a different trend is shown and no increase in viscosity of the blends with the two LCB-PPs and the commercially available HMS-PP could be achieved.

In addition to the viscosity curves, the curves of the storage and loss moduli were also studied, as well as their crossover points. In principle, an increase in molecular weight as 
well as a broadening of the molecular weight distribution could be achieved by using the blend materials compared to the respective starting material. However, the flakes of the recycled bucket were an exception. In the specified measuring range an approximation between the storage modulus curve and the loss modulus curve can be recognized but no corssover point could be measured for this series and thus no statement could be made.

However, in order to determine whether strain hardening also occurs due to the use of the respective blending materials, the elongational rheology was also investigated in addition to the dynamic rheology. Here, a large difference was found between the linear PP as blend material compared to the two LCB-PPs and the commercially available HMS-PP. The starting materials as well as the series blended with the linear PP showed no strain hardening and thus no melt stiffness. However, the blend series with the two LCB-PPs and the commercial HMS-PP showed strain hardening throughout. Comparing the blends with each other and contrast the series with the linear PP with those of the LCB-PPs, the two blend series with the respective LCB-PPs have the advantage that a melt stiffness occurs with them and thus a significant strain-hardening effect occurs. If one compares these two series with the blend series of the commercial HMS-PP, these two can simply keep up in terms of elongation rheology.

In the case of the mechanical properties, especially elongation at break and tensile impact strength, different results could be achieved by using the respective blends, which were consistently better for all blends compared to the starting material. By using commercial PP and HMS-PP, the properties could be increased compared to the virgin materials. However, by blending with LCB-PP this could be increased even more in comparison to the blends with PP or HMS-PP. Finally, for the LCB-PP on the basis of PODIC C126 with the LCB-PP on the basis of PEROXAN LP, both are comparable.

For the thermal characterization, DSC measurements of the starting materials as well as the corresponding blends were performed. The use of the different blends did not result in any changes in the melting temperature compared to the starting material. When analyzing the crystallization temperature, only the blends with HMS-PP showed an increase, whereas the crystallization temperature of the other blends remained uneffected. The degree of crystallization was also not significantly affected by the blending of the individual materials. The only exceptions were the two blends with LCB-PP based on PODIC C126 or PEROXAN LP, which were added to the flakes of buckets. Here an increase in crystallinity could be detected.

The SEM measurements clearly showed the miscibility of the individual blends with the respective start materials. In particular, when comparing the SEM photos of the virgin/recycled material with the blend series, no influence of the blends could be detected and thus no particle contamination could be verified. In addition, by using FTIR measurements, it could be verified that the modified LCB-PPs used for blending showed the characteristic band for the carbonyl group of an ester at $1743 \mathrm{~cm}^{-1}$ for all virgin/recycled materials even after extrusion at $240{ }^{\circ} \mathrm{C}$.

According to theses results, by using $10 \mathrm{wt}$ \% LCB-PP based on PODIC C126 or PEROXAN LP, the properties of recyclates can be upgraded, leading to an actual upcycling of these materials. This makes it possible to specifically the use the recyclates in other areas of application where a higher melt strength is desired or required.

Supplementary Materials: The following are available online at https:/ / www.mdpi.com/article/10 .3390 / polym13071137/s1, Figure S1: DSC curses of the second heating of the investigated materials; (a) PP3, (b) PP4, (c) flakes of coffee caps, (d) flakes of yoghurt cups, (e) flakes of buckets.

Author Contributions: Conceptualization, S.S.; methodology, S.S. and T.K.; validation, S.S., T.K. and V.-M.A.; formal analysis, S.S.; investigation, S.S.; resources, K.S.; writing-original draft preparation, S.S.; writing-review and editing, S.S., T.K. and V.-M.A.; visualization, S.S.; supervision, K.S., S.K. and V.-M.A.; project administration, S.S.; funding acquisition, V.-M.A. All authors have read and agreed to the published version of the manuscript. 
Funding: This research was funded by FFG, Recycling Healing of polyOlefins (RHO); project number 867903 .

Institutional Review Board Statement: Not applicable.

Informed Consent Statement: Not applicable.

Data Availability Statement: Not applicable.

Acknowledgments: The authors acknowledge TU Wien University Library for financial support through its Open Access Funding Programme. The authors would like to thank Walter Kunststoffe $\mathrm{GmbH}$ for providing the recycled materials and for their support.

Conflicts of Interest: The authors declare no conflict of interest.

\section{Appendix A}

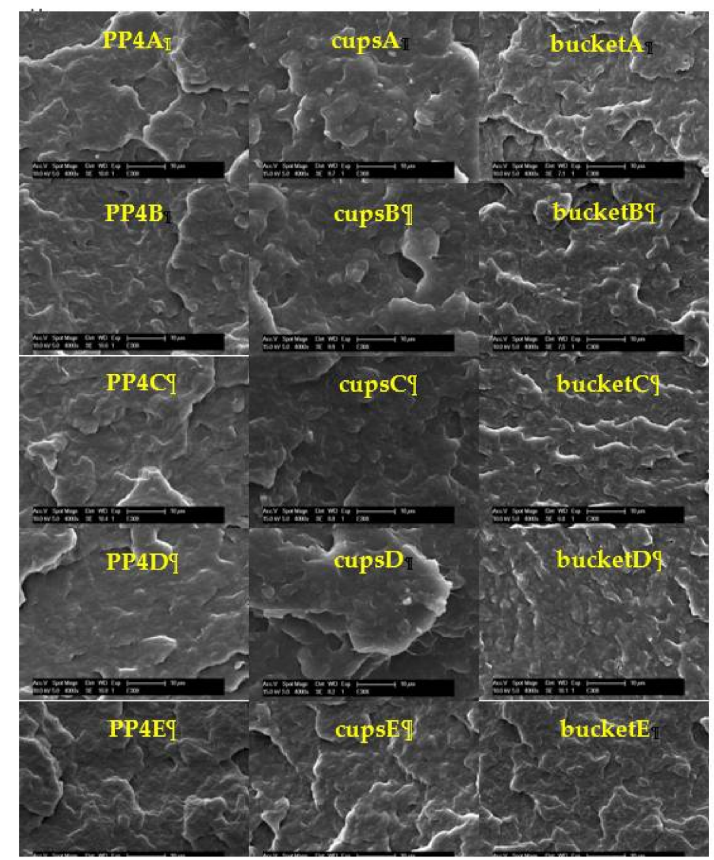

Figure A1. SEM images of the virgin material of PP4 and the recycled flakes of cups and bucket (A) and the blend series on basis of PP2 (B), LCB-PP with PODIC C126 (C), LCB-PP with PEROXAN LP (D), HMS-PP (E).

\section{References}

1. Plastic Europe. Plastics_The Facts 2019; Plastic Europe: Brussels, Belgium, 2020.

2. Pasquini, N.; Addeo, A. (Eds.) Polypropylene Handbook; Hanser Publications: Munich, Germany, 2005.

3. Al-Salem, S.M.; Lettieri, P.; Baeyens, J. Recycling and recovery routes of plastic solid waste (PSW): A review. Waste Manag. 2009, 29, 2625-2643. [CrossRef] [PubMed]

4. Lazarevic, D.; Aoustin, E.; Buclet, N.; Brandt, N. Plastic waste management in the context of a European recycling society: Comparing results and uncertainties in a life cycle perspective. Resour. Conserv. Recycl. 2010, 55, 246-259. [CrossRef]

5. Gu, F.; Hall, P.; Miles, N.J. Performance evaluation for composites based on recycled polypropylene using principal component analysis and cluster analysis. J. Clean. Prod. 2016, 115, 343-353. [CrossRef]

6. Gu, F.; Hall, P.; Miles, N.J. Development of composites based on recycled polypropylene for injection moulding automobile parts using hierarchical clustering analysis and principal component estimate. J. Clean. Prod. 2016, 137, 632-643. [CrossRef]

7. Wäger, P.A.; Hischier, R. Life cycle assessment of post-consumer plastics production from waste electrical and electronic equipment (WEEE) treatment residues in a Central European plastics recycling plant. Sci. Total Environ. 2015, 529, 158-167. [CrossRef] [PubMed]

8. Al-Maaded, M.; Madi, N.K.; Kahraman, R.; Hodzic, A.; Ozerkan, N.G. An Overview of Solid Waste Management and Plastic Recycling in Qatar. J. Polym. Environ. 2012, 20, 186-194. [CrossRef]

9. Strapasson, R.; Amico, S.C.; Pereira, M.F.R.; Sydenstricker, T.H.D. Tensile and impact behavior of polypropylene/low density polyethylene blends. Polym. Test. 2005, 24, 468-473. [CrossRef] 
10. Meran, C.; Ozturk, O.; Yuksel, M. Examination of the possibility of recycling and utilizing recycled polyethylene and polypropylene. Mater. Des. 2008, 29, 701-705. [CrossRef]

11. Brachet, P.; Høydal, L.T.; Hinrichsen, E.L.; Melum, F. Modification of mechanical properties of recycled polypropylene from post-consumer containers. Waste Manag. 2008, 28, 2456-2464. [CrossRef]

12. Kowalska, E.; Wielgosz, Z.; Pelka, J. Use of Post-Life Waste and Production Waste in Thermoplastic Polymer Compositions. Polym. Polym. Compos. 2002, 10, 83-92. [CrossRef]

13. Tri Phuong, N.; Gilbert, V.; Chuong, B. Preparation of Recycled Polypropylene/Organophilic Modified Layered Silicates Nanocomposites Part I: The Recycling Process of Polypropylene and the Mechanical Properties of Recycled Polypropylene/Organoclay Nanocomposites. J. Reinf. Plast. Compos. 2008, 27, 1983-2000. [CrossRef]

14. Bahlouli, N.; Pessey, D.; Raveyre, C.; Guillet, J.; Ahzi, S.; Dahoun, A.; Hiver, J.M. Recycling effects on the rheological and thermomechanical properties of polypropylene-based composites. Mater. Des. 2012, 33, 451-458. [CrossRef]

15. Bourmaud, A.; Baley, C. Rigidity analysis of polypropylene/vegetal fibre composites after recycling. Polym. Degrad. Stab. 2009, 94, 297-305. [CrossRef]

16. Dehghani, A.; Madadi Ardekani, S.; Al-Maadeed, M.A.; Hassan, A.; Wahit, M.U. Mechanical and thermal properties of date palm leaf fiber reinforced recycled poly (ethylene terephthalate) composites. Mater. Des. 2013, 52, 841-848. [CrossRef]

17. Al-Maadeed, M.A.; Shabana, Y.M.; Khanam, P.N. Processing, characterization and modeling of recycled polypropylene/glass fibre/wood flour composites. Mater. Des. 2014, 58, 374-380. [CrossRef]

18. Sommerhuber, P.F.; Welling, J.; Krause, A. Substitution potentials of recycled HDPE and wood particles from post-consumer packaging waste in Wood-Plastic Composites. Waste Manag. 2015, 46, 76-85. [CrossRef]

19. Sommerhuber, P.F.; Wang, T.; Krause, A. Wood-plastic composites as potential applications of recycled plastics of electronic waste and recycled particleboard. J. Clean. Prod. 2016, 121, 176-185. [CrossRef]

20. Vazquez, Y.V.; Barbosa, S.E. Recycling of mixed plastic waste from electrical and electronic equipment. Added value by compatibilization. Waste Manag. 2016, 53, 196-203. [CrossRef] [PubMed]

21. Kamleitner, F.; Duscher, B.; Koch, T.; Knaus, S.; Archodoulaki, V.M. Upcycling of polypropylene-The influence of polyethylene impurities. Polym. Eng. Sci. 2017, 57, 1374-1381. [CrossRef]

22. Jahani, Y.; Ghetmiri, M.; Vaseghi, M.R. The effects of long chain branching of polypropylene and chain extension of poly(ethylene terephthalate) on the thermal behavior, rheology and morphology of their blends. RSC Adv. 2015, 5, 21620-21628. [CrossRef]

23. Nam, G.J.; Yoo, J.H.; Lee, J.W. Effect of long-chain branches of polypropylene on rheological properties and foam-extrusion performances. J. Appl. Polym. Sci. 2005, 96, 1793-1800. [CrossRef]

24. Gotsis, A.D.; Zeevenhoven, B.L.F.; Hogt, A.H. The effect of long chain branching on the processability of polypropylene in thermoforming. Polym. Eng. Sci. 2004, 44, 973-982. [CrossRef]

25. Tian, J.; Yu, W.; Zhou, C.J.P. The preparation and rheology characterization of long chain branching polypropylene. Polymer 2006, 47, 7962-7969. [CrossRef]

26. Stange, J.; Münstedt, H. Rheological properties and foaming behavior of polypropylenes with different molecular structures. $J$. Rheol. 2006, 50, 907-923. [CrossRef]

27. Passaglia, E.; Coiai, S.; Cicogna, F.; Ciardelli, F. Some recent advances in polyolefin functionalization. Polym. Int. 2014, 63, 12-21. [CrossRef]

28. Parent, J.S.; Bodsworth, A.; Sengupta, S.S.; Kontopoulou, M.; Chaudhary, B.I.; Poche, D.; Cousteaux, S. Structure-rheology relationships of long-chain branched polypropylene: Comparative analysis of acrylic and allylic coagent chemistry. Polymer 2009, 50, 85-94. [CrossRef]

29. El Mabrouk, K.; Parent, J.S.; Chaudhary, B.I.; Cong, R. Chemical modification of PP architecture: Strategies for introducing long-chain branching. Polymer 2009, 50, 5390-5397. [CrossRef]

30. Kim, D.Y.; Cha, J.H.; Seo, K.H. Effects of chain extender on properties and foaming behavior of polypropylene foam. RSC Adv. 2019, 9, 25496-25507. [CrossRef]

31. Weng, W.; Hu, W.; Dekmezian, A.H.; Ruff, C.J. Long chain branched isotactic polypropylene. Macromolecules 2002, 35, 3838-3843. [CrossRef]

32. Langston, J.A.; Colby, R.H.; Chung, T.C.M.; Shimizu, F.; Suzuki, T.; Aoki, M. Synthesis and Characterization of Long Chain Branched Isotactic Polypropylene via Metallocene Catalyst and T-Reagent. Macromolecules 2007, 40, 2712-2720. [CrossRef]

33. Krause, B.; Stephan, M.; Volkland, S.; Voigt, D.; Häußler, L.; Dorschner, H. Long-chain branching of polypropylene by electronbeam irradiation in the molten state. J. Appl. Polym. Sci. 2006, 99, 260-265. [CrossRef]

34. Lugão, A.B.; Otaguro, H.; Parra, D.F.; Yoshiga, A.; Lima, L.F.C.P.; Artel, B.W.H.; Liberman, S. Review on the production process and uses of controlled rheology polypropylene-Gamma radiation versus electron beam processing. Radiat. Phys. Chem. 2007, 76, 1688-1690. [CrossRef]

35. Ali, Z.I.; Youssef, H.A.; Said, H.M.; Saleh, H.H. Influence of electron beam irradiation and polyfunctional monomer loading on the physico-chemical properties of polyethylene/polypropylene blends. Adv. Polym. Technol. J. Polym. Process. Inst. 2006, 25, 208-217. [CrossRef]

36. Graebling, D. Synthesis of Branched Polypropylene by a Reactive Extrusion Process. Macromolecules 2002, 35, 4602-4610. [CrossRef] 
37. Su, F.H.; Huang, H.X. Rheology and thermal behavior of long branching polypropylene prepared by reactive extrusion. J. Appl. Polym. Sci. 2009, 113, 2126-2135. [CrossRef]

38. Yamaguchi, M.; Wagner, M.H. Impact of processing history on rheological properties for branched polypropylene. Polymer 2006, 47, 3629-3635. [CrossRef]

39. Kamleitner, F.; Duscher, B.; Koch, T.; Knaus, S.; Schmid, K.; Archodoulaki, V.-M. Influence of the Molar Mass on Long-Chain Branching of Polypropylene. Polymers 2017, 9, 442. [CrossRef]

40. Stanic, S.; Gottlieb, G.; Koch, T.; Göpperl, L.; Schmid, K.; Knaus, S.; Archodoulaki, V.-M. Influence of Different Types of Peroxides on the Long-Chain Branching of PP via Reactive Extrusion. Polymers 2020, 12, 886. [CrossRef]

41. Maris, J.; Bourdon, S.; Brossard, J.-M.; Cauret, L.; Fontaine, L.; Montembault, V. Mechanical recycling: Compatibilization of mixed thermoplastic wastes. Polym. Degrad. Stab. 2018, 147, 245-266. [CrossRef]

42. Moad, G. The synthesis of polyolefin graft copolymers by reactive extrusion. Prog. Polym. Sci. 1999, 24, 81-142. [CrossRef]

43. Moore Junior, E. Polypropylene Handbook: Polymerization, Characterization, Properties, Processing, Applications; Hanser Publishers: New York, NY, USA, 1996.

44. Zweifel, H.; Maier, R.D.; Schiller, M.; Amos, S.E. Plastics Additives Handbook; Hanser Pub Inc.: Munich, Germany, 2001.

45. Azizi, H.; Ghasemi, I. Reactive extrusion of polypropylene: Production of controlled-rheology polypropylene (CRPP) by peroxide-promoted degradation. Polym. Test. 2004, 23, 137-143. [CrossRef]

46. Azizi, H.; Ghasemi, I.; Karrabi, M. Controlled-peroxide degradation of polypropylene: Rheological properties and prediction of MWD from rheological data. Polym. Test. 2008, 27, 548-554. [CrossRef]

47. Stange, J.; Uhl, C.; Münstedt, H. Rheological behavior of blends from a linear and a long-chain branched polypropylene. J. Rheol. 2005, 49, 1059-1079. [CrossRef]

48. Fang, Y.; Sadeghi, F.; Fleuret, G.; Carreau, P.J. Properties of blends of linear and branched polypropylenes in film blowing. Can. J. Chem. Eng. 2008, 86, 6-14. [CrossRef]

49. McCallum, T.J.; Kontopoulou, M.; Park, C.B.; Muliawan, E.B.; Hatzikiriakos, S.G. The rheological and physical properties of linear and branched polypropylene blends. Polym. Eng. Sci. 2007, 47, 1133-1140. [CrossRef]

50. Stanic, S.; Koch, T.; Schmid, K.; Knaus, S.; Archodoulaki, V.-M. Upcycling of polypropylene with various concentrations of peroxydicarbonate and dilauroyl peroxide and two processing steps. J. Appl. Polym. Sci. 2021, 50659. [CrossRef]

51. ISO 1133. Plastics-Determination of the Melt Mass-Flow Rate (MFR) and Melt Volume-Flow Rate (MVR) of Thermoplastics-Part 1: Standard Method; ISO: Geneva, Switzerland, 2011.

52. ISO 527. Plastics—Determination of Tensile Properties—Part 2: Test Conditions for Moulding and Extrusion Plastics; ISO: Geneva, Switzerland, 2012.

53. ISO 8256. Plastics—Determination of Tensile-Impact Strength; ISO: Geneva, Switzerland, 2004.

54. Lagendijk, R.P.; Hogt, A.H.; Buijtenhuijs, A.; Gotsis, A.D. Peroxydicarbonate modification of polypropylene and extensional flow properties. Polymer 2001, 42, 10035-10043. [CrossRef]

55. Zhou, S.; Zhou, J.; Li, L.; Zhao, S.; Shi, Y.; Xin, Z. Relationship between Peroxide Initiators and Properties of Styrene Grafted Polypropylene via Reactive Extrusion. J. Macromol. Sci. Part B 2018, 57, 377-394. [CrossRef]

56. An, Y.; Zhang, Z.; Bi, W.; Wang, Y.; Tang, T. Characterization of high melt strength polypropylene synthesized via silane grafting initiated by in situ heat induction reaction. J. Appl. Polym. Sci. 2008, 110, 3727-3732. [CrossRef]

57. Drabek, J.; Zatloukal, M.; Martyn, M. Effect of molecular weight, branching and temperature on dynamics of polypropylene melts at very high shear rates. Polymer 2018, 144, 179-183. [CrossRef]

58. Su, F.-H.; Huang, H.-X. Influence of polyfunctional monomer on melt strength and rheology of long-chain branched polypropylene by reactive extrusion. J. Appl. Polym. Sci. 2010, 116, 2557-2565. [CrossRef]

59. Su, F.-H.; Huang, H.-X. Rheology and melt strength of long chain branching polypropylene prepared by reactive extrusion with various peroxides. Polym. Eng. Sci. 2010, 50, 342-351. [CrossRef]

60. Sugimoto, M.; Masubuchi, Y.; Takimoto, J.; Koyama, K. Melt rheology of polypropylene containing small amounts of high molecular weight chain. I. Shear flow. J. Polym. Sci. Part B Polym. Phys. 2001, 39, 2692-2704. [CrossRef]

61. Wong, B.; Baker, W.J.P. Melt rheology of graft modified polypropylene. Polymer 1997, 38, 2781-2789. [CrossRef]

62. Malmberg, A.; Gabriel, C.; Steffl, T.; Münstedt, H.; Löfgren, B. Long-Chain Branching in Metallocene-Catalyzed Polyethylenes Investigated by Low Oscillatory Shear and Uniaxial Extensional Rheometry. Macromolecules 2002, 35, 1038-1048. [CrossRef]

63. Larson, R.G. The Structure and Rheology of Complex Fluids; Oxford University Press: New York, NY, USA, 1999 ; Volume 150.

64. Wang, L.; Wan, D.; Zhang, Z.; Liu, F.; Xing, H.; Wang, Y.; Tang, T. Synthesis and Structure-Property Relationships of Polypropyleneg-poly(ethylene-co-1-butene) Graft Copolymers with Well-Defined Long Chain Branched Molecular Structures. Macromolecules 2011, 44, 4167-4179. [CrossRef]

65. Ajji, A.; Sammut, P.; Huneault, M.A. Elongational rheology of LLDPE/LDPE blends. J. Appl. Polym. Sci. 2003, 88, 3070-3077. [CrossRef]

66. Bernreitner, K.; Neißl, W.; Gahleitner, M. Correlation between molecular structure and rheological behaviour of polypropylene. Polym. Test. 1992, 11, 89-100. [CrossRef]

67. Mezger, T.G. The Rheology Handbook: For Users of Rotational and Oscillatory Rheometers; Vincentz Network GmbH \& Co KG: Hannover, Germany, 2006. 
68. Tzoganakis, C. A rheological evaluation of linear and branched controlled-rheology polypropylenes. Can. J. Chem. Eng. 1994, 72, 749-754. [CrossRef]

69. Morshedian, J.; Karbalaei-Bagher, M.; Bayazian, H.; Jamshidi, A.; Razavi-Nouri, M. Unraveling the Bimodality of Polypropylene Film Grades Using Rheological Shear and Elongational Measurements: Inconsistent Results of Gel Permeation Chromatography. Polym. Sci. Ser. A 2018, 60, 523-529. [CrossRef]

70. Fleissner, M. Characterization of polymer molecular mass distribution from rheological measurements. In Makromolekulare Chemie. Macromolecular Symposia; Hüthig \& Wepf Verlag: Basel, Switzerland, 1992; Volume 61, pp. 324-341. [CrossRef]

71. Borg, T.; Pääkkönen, E.J. Linear viscoelastic models: Part II. Recovery of the molecular weight distribution using viscosity data. J. Non-Newton. Fluid Mech. 2009, 156, 129-138. [CrossRef]

72. Malkin, A.Y.; Teishev, A.E. Flow curve-molecular weight distribution: Is the solution of the inverse problem possible? Polym. Eng. Sci. 1991, 31, 1590-1596. [CrossRef]

73. Friedrich, C.; Loy, R.J.; Anderssen, R.S. Relaxation time spectrum molecular weight distribution relationships. Rheol. Acta 2008, 48, 151. [CrossRef]

74. Gotsis, A.D.; Zeevenhoven, B.L.F.; Tsenoglou, C. Effect of long branches on the rheology of polypropylene. J. Rheol. 2004, 48, 895-914. [CrossRef]

75. Kamleitner, F.; Duscher, B.; Koch, T.; Knaus, S.; Archodoulaki, V.-M. Long chain branching as an innovative up-cycling process of polypropylene post-consumer waste-Possibilities and limitations. Waste Manag. 2017, 68, 32-37. [CrossRef]

76. Münstedt, H.; Auhl, D. Rheological measuring techniques and their relevance for the molecular characterization of polymers. J. Non-Newton. Fluid Mech. 2005, 128, 62-69. [CrossRef]

77. Münstedt, H.; Laun, H.M. Elongational properties and molecular structure of polyethylene melts. Rheol. Acta 1981, 20, $211-221$. [CrossRef]

78. Spitael, P.; Macosko, C.W. Strain hardening in polypropylenes and its role in extrusion foaming. Polym. Eng. Sci. 2004, 44, 2090-2100. [CrossRef]

79. Dealy, J.M.; Wissbrun, K.F. Melt Rheology and Its Role in Plastics Processing: Theory and Applications; Springer: Berlin/Heidelberg, Germany, 2012.

80. Stadler, F.J.; Nishioka, A.; Stange, J.; Koyama, K.; Münstedt, H. Comparison of the elongational behavior of various polyolefins in uniaxial and equibiaxial flows. Rheol. Acta 2007, 46, 1003-1012. [CrossRef]

81. Duscher, B.; Schausberger, A. Influence of processing on the flow properties of long-chain branched polypropylene. Polym. Eng. Sci. 2018, 58, 1596-1603. [CrossRef]

82. Seier, M.; Stanic, S.; Koch, T.; Archodoulaki, V.-M. Effect of Different Compatibilization Systems on the Rheological, Mechanical and Morphological Properties of Polypropylene/Polystyrene Blends. Polymers 2020, 12, 2335. [CrossRef]

83. Münstedt, H. Extensional Rheology and Processing of Polymeric Materials. Int. Polym. Process. 2018, 33, 594-618. [CrossRef]

84. Vlachopoulos, J.; Polychronopoulos, N.; Kontopoulou, M. Basic Concepts in Polymer Melt Rheology and Their Importance in Processing. Appl. Polym. Rheol. 2011, 1-27. [CrossRef]

85. Trouton, F.T. On the coefficient of viscous traction and its relation to that of viscosity. Proc. R. Soc. Lond. Ser. A Contain. Pap. Math. Phys. Character 1906, 77, 426-440. [CrossRef]

86. Tabatabaei, S.H.; Carreau, P.J.; Ajji, A. Rheological and thermal properties of blends of a long-chain branched polypropylene and different linear polypropylenes. Chem. Eng. Sci. 2009, 64, 4719-4731. [CrossRef]

87. Lampman, S. Characterization and Failure Analysis of Plastics; ASM International: Almere, The Netherlands, 2003.

88. Grellmann, W.; Seidler, S. Kunststoffprüfung; Carl Hanser Verlag GmbH Co KG: Munich, Germany, 2015.

89. Mark, J.E. Physical Properties of Polymers Handbook; Springer: Berlin/Heidelberg, Germany, 2007; Volume 1076.

90. Cao, J.; Wen, N.; Zheng, Y.-Y. Effect of long chain branching on the rheological behavior, crystallization and mechanical properties of polypropylene random copolymer. Chin. J. Polym. Sci. 2016, 34, 1158-1171. [CrossRef]

91. Li, Y.; Jia, S.; Du, S.; Wang, Y.; Lv, L.; Zhang, J. Improved properties of recycled polypropylene by introducing the long chain branched structure through reactive extrusion. Waste Manag. 2018, 76, 172-179. [CrossRef]

92. Wang, X.; Tzoganakis, C.; Rempel, G.L. Chemical modification of polypropylene with peroxide/pentaerythritol triacrylate by reactive extrusion. J. Appl. Polym. Sci. 1996, 61, 1395-1404. [CrossRef]

93. Flores, M.; Fernández-Francos, X.; Ramis, X.; Serra, A. Novel epoxy-anhydride thermosets modified with a hyperbranched polyester as toughness enhancer. I. Kinetics study. Thermochim. Acta 2012, 544, 17-26. [CrossRef] 